\title{
PERANCANGAN KOMUNIKASI VISUAL FILM ANIMASI PENDEK “DEWI YANG KESEPIAN"
}

\author{
Pamela Suryajaya; Dyah Gayatri Puspitasari \\ Jurusan Desain Komunikasi Visual, Fakultas Komunikasi dan Multimedia, BINUS University \\ Jln. K.H. Syahdan No. 9, Kemanggisan, Palmerah, Jakarta Barat 11480
}

\begin{abstract}
This research is to gain, collecting, and analyze data needed to design short movie animation in 3 dimension technique about gods and goddesses myth in visually attractive so it could attract teenage audiences to send the message. The research method is direct survey to the location, i.e. Pura Merthasari, Wihara Dharma Bhakti (Klenteng Petak Sembilan), National Museum, and library. Besides, it is supported by literature media like books, magazines, and journals and internet references related to topic. The expected result is to reissue the cultural richness of myth in Indonesia so that it could be disseminated in to the myth animation film of gods and goddesses. The overall conclusion in today's era is that visual communication media like film and television show are attracted teenagers. Therefore, by using animation film media, teenagers will be interested and attracted in national's gods and goddesses myth, because the local show is just like international show.
\end{abstract}

Keywords: animation, mythology, myth, moral value

\begin{abstract}
ABSTRAK
Penelitian ini untuk memperoleh, mengumpulkan dan menganalisa data-data yang dibutuhkan untuk mewujudkan perancangan film animasi pendek dengan teknik 3 Dimensi yang bertemakan mitologi Dewa Dewi dengan visual menarik agar dapat menarik minat penonton khususnya remaja sehingga pesan moral dapat tersampaikan. Metode penelitian yang digunakan adalah dengan survei langsung ke lapangan, yaitu ke Pura Merthasari, Wihara Dharma Bhakti (Klenteng Petak Sembilan), Museum Nasional dan perpustakaan. Selain itu juga dengan media literatur seperti buku, majalah dan jurnal serta didukung dengan referensi dari media internet yang berhubungan dengan topik. Hasil yang ingin dicapai adalah dapat mengangkat kembali kekayaan budaya mitologi Indonesia dan agar pesan moral yang ingin disampaikan dalam film animasi mitos dewa dewi ini dapat tersalurkan dan dimengerti oleh penonton, khususnya remaja. Simpulannya pada masa sekarang ini, media komunikasi visual seperti film dan tayangan televisi sangat digemari remaja. Maka dengan menggunakan media film animasi, remaja akan lebih tertarik dan bisa menyukai mitologi dewa dewi Nusantara, karena tayangan lokal tidak kalah dengan tayangan luar.
\end{abstract}

Kata kunci: animasi, mitologi, mitos, pesan moral 


\section{PENDAHULUAN}

Indonesia adalah negeri yang kaya akan kebudayaan dan kesenian lokal, karena keberagaman suku dan adat istiadat membuat Indonesia menjadi negeri yang sangat unik dengan banyak kisah dan latar belakang yang menarik seperti budaya mitologi tentang dewa dewi yang diyakini masyarakat setiap daerah asalnya. Hal ini mendapat pengaruh kuat dari perkembangan agama Hindu dan Budha di Indonesia. Penyebarannya banyak dilakukan oleh para pendeta maupun tokoh agama setempat dan para pedagang Cina dan India. Mitologi dewa dewi sendiri juga telah meluas di berbagai negeri lain, tidak jarang dewa dewi yang sama mempunyai berbagai versi cerita. Pesan moral biasanya berupa ajaran kesucian, keluhuran, keteguhan dan kesabaran dalam menghadapi dan menjalankan hidup.

Pada masa sekarang ini, mitos dewa dewi Nusantara kurang diminati oleh para remaja. Dengan semakin berkembangnya teknologi dan media komunikasi serta pengaruh unsur luar negeri, membuat para remaja Nusantara tidak lagi begitu mengenal dan mencintai budaya serta seni lokal. Banyaknya jenis cerita dari luar negeri, membuat mereka beralih untuk lebih meminati jenis cerita tersebut, padahal cerita rakyat maupun mitologi dewa dewi Nusantara sendiri begitu kaya, memikat dan memiliki banyak sekali manfaat dan orisinalitas budaya yang bisa diperoleh .Cerita rakyat maupun mitologi dewa dewi Nusantara tentunya memiliki kesan sejarah dan budaya yang kental, sehingga dapat mengajak generasi muda untuk bisa mencintai dan lebih mengenal budaya bangsa sendiri. Namun dengan segala manfaat yang ada, materi mengenai mitos dewa dewi Nusantara ini tetap saja tidak terlalu tersampaikan ke masyarakat luas, khususnya ke target para remaja. Alasan yang biasanya terjadi adalah karena mitos dewa dewi dengan tampilan tradisional terlihat tidak menarik, monoton, usang dan dianggap tidak cocok dengan perkembangan jaman modern.

Mengingat perkembangan animasi di Indonesia semakin berkembang pesat dan mulai menjadi bagian hidup dari para remaja maka dengan bantuan elektronik, mitos dewa dewi Nusantara dapat dilestarikan dan disebarkan dengan lebih efektif dan dikemas dengan menarik. Pesan moral pun bisa tersampaikan dan dapat tetap dinikmati audiense dengan metode penyampaian film animasi yang baik. Dengan bentuk visual serta karakter yang menarik maka akan lebih dapat menarik minat para remaja untuk menkonsumsinya dengan tetap mendapatkan pesan moral yang mendidik. Sehingga dengan demikian, kekayaan dan warisan budaya bangsa tetap terjaga dan terpelihara serta penanaman rasa cinta bangsa, pengembangan wawasan kontent lokal bagi generasi muda tercapai optimal.

Berdasarkan pada fakta dan situasi tersebut di dalam kaitannya dengan bidang studi Desain Komunikasi Visual, maka lingkup yang dibahas dibatasi pada hal-hal yang dapat ditangani atau diselesaikan melalui pendekatan DKV, yaitu dengan membuat komunikasi audio visual mengenai cerita pendek animasi yang dibuat dengan 3D Animation, full narasi, tanpa dialog dengan tema mitos Dewi Bulan dan Dewa Matahari masyarakat Jambi yang merupakan akulturasi dari mitologi dewa dewi Cina dengan tampilan karakter yang dimodifikasi dengan budaya Jawa dan Bali. Cerita ini mengisahkan tentang kisah asmara antara Dewi Bulan yang merindukan Dewa Matahari dengan judul Dewi yang Kesepian atau The Lonely Goddess dalam versi bahasa Inggrisnya. Kisah ini menggambarkan kesetiaan Dewi Bulan dalam penantiannya yang begitu panjang selama 360 tahun untuk dapat bertemu dengan pujaan hatinya Dewa Matahari walau pertemuan itu sendiri hanya dapat berlangsung begitu singkat yaitu pada saat terjadinya gerhana matahari total.

Tujuan pembuatan film animasi pendek ini untuk menanamkan pesan moral terhadap para remaja agar memahami pentingnya arti kesabaran, rasa kasih sayang, kesetiaan, keyakinan dan keteguhan hati dalam pengembanan suatu tugas yang kepentingannya jauh melebihi kepentingan sendiri. Tujuan untuk menghibur para penonton pun juga dapat tersampaikan dengan pengolahan visual animasi yang dikemas dengan kualitas yang baik dan menarik. Dengan semua tujuan diatas bisa tercapai, maka tujuan untuk melestarikan dan memperkenalkan kembali budaya lokal kepada anak bangsa dapat terpenuhi. 
Bahasan akan mengulas tentang bagaimana merancang komunikasi audio visual dengan film animasi pendek bertema mitologi Dewi Bulan dan Dewa Matahari agar menarik minat para remaja sehingga pesan moral serta pelestarian budaya lokal tersampaikan dengan tetap memberikan hiburan bagi penonton. Juga bagaimana untuk menghidupkan kembali budaya mitologi dewa dewi Nusantara di hati para remaja.

\section{METODE}

Metode penelitian yang digunakan adalah berdasarkan studi literature tercetak maupun elektronik dan kunjungan secara langsung ke Pura Merthasari, Wihara Dharma Bhakti (Klenteng Petak Sembilan), Museum Nasional. Survei target audience, dan terakhir tahap perancangan visual jalan cerita yang bermuasal dari masyarakat Jambi yg merupakan akulturasi mitologi dewa dewi Cina, dan tahap perancangan visual penciptaan karakter desain tokoh dan suasana lingkugan dengan modifikasi perpaduan karakter budaya Jawa dan Bali.

\section{PEMBAHASAN}

Pesan moral yang disampaikan dari hasil film animasi pendek mitologi dewa dewi ini adalah bagaimana seseorang harus selalu dapat meyakini dirinya sendiri untuk dapat tetap tabah, sabar, setia, memelihara rasa kasih sayang, kuat dan teguh dalam mengemban tugasnya dan selalu dapat menjunjung tinggi kepentingan yang lebih besar dibanding kepentingannya sendiri.

Film dirancang dalam bentuk film animasi pendek dengan durasi sekitar 6-7 menit dibuat dengan dua versi bahasa yaitu bahasa Indonesia dan bahasa Inggris,dimana di dalamnya terdapat pembukaan, inti cerita, klimaks, solusi cerita, akhir cerita bagian credit pembuat film. Film dilengkapi dengan narasi, musik dan efek suara untuk mendukung kelengkapan dari film mitologi dewa dewi ini berikut pesan moral yang ditujukan kepada penonton yang khususnya adalah para remaja.

Dari berbagai versi mitos tentang Dewi Bulan yang ada, seperti versi mitologi Hindu India, mitologi Hindu Bali dan mitologi pewayangan Jawa, isi cerita film animasi pendek ini lebih mengadopsi mitologi Dewi Bulan dan Dewa matahari dari masyarakat Jambi yang merupakan akulturasi dari mitologi dewa dewi Cina, dimana dewi bulan Chang E akan tinggal abadi di bulan sedangkan suaminya Houyi atau Satria akan dikirim ke matahari sehingga mereka bisa menerangi bumi secara bergantian. Ironi dalam cerita ini adalah bagaimana bulan dan matahari yang saling mencintai namun selalu terpisahkan. Mereka hanya dapat bertemu setiap 360 tahun sekali yaitu pada saat gerhana matahari total dan itupun hanya dapat berlangsung dalam waktu yang begitu singkat yaitu selama7 menit. Namun keduanya ikhlas menerima kondisi tersebut demi mengemban tugasnya sebagi pemberi keseimbangan di bumi. Judul film dipilih dengan judul Dewi yang Kesepian dan The Lonely Goddess dalam versi bahasa Inggrisnya.

\section{Perancangan Sinopsis dan Skenario}

Setelah melalui penyesuaian emphasis jalan cerita dan panjangnya durasi maka selanjutnya sinopsis cerita disusun menjadi sebagai berikut.

Ada yang mengatakan satu tahun merupakan waktu yang lama. Bagaimana dengan 360 tahun? Sang Dewi Bulan tinggal sendirian di langit malam yang gelap dan sepi, iapun merasa sangat kesepian. Sayangnya hal yang bisa membuatnya tersenyum hanyalah ketika 
untuk sekejap saja ia bisa melihat sang Dewa Matahari. Mereka saling mencintai dan terus mencoba untuk saling menggapai, namun takdir memisahkan dan memaksa mereka untuk tidak bersatu. Bulan naik ketika matahari turun, dan matahari naik ketika bulan turun. Sang Dewa Matahari marah besar karena ia tidak bisa bertemu dengan kekasihnya, menyebabkan suasana siang dibumi semakin panas dan terik. Sedangkan malam hari menjadi semakin kelam, akibat Dewi Bulan yang semakin bersedih. Merekapun akhirnya pasrah, terus menatap keatas dan bertanya kapan dan apakah mereka sudah bisa dipertemukan? Sudah tak terhitung berapa putaran dan hari yang mereka lalui. Hingga akhirnya, genap 360 tahun sudah mereka terpisahkan. Mereka bertemu ketika gerhana matahari total. Sayangnya pertemuan tersebutpun hanya sebentar, dari 360 tahun mereka menunggu, 7 menit adalah waktu yang diberikan sang Maha Kuasa. Sebelum akhirnya mereka kembali ke posisi masing, menerangi bumi disiang dan malam hari. Untuk selanjutnya mereka dengan ikhlas dan sabar menanti 360 tahun lagi pertemuan mereka sambil terus berperan sebagai pemberi keseimbangan bagi sang bumi.

Selanjutya dituangkan dalam skenario, seperti di bawah ini.

\section{ACT 1- INTRO}

FADE IN:

EXT. BUMI-SIANG

Shot dari angle bawah pohon-pohon palem.

FADE OUT

EXT. BUMI- SORE

Medium shot pohon-pohon palem di sore hari dengan suara kicauan burung.

FADE OUT

EXT. BUMI- MALAM

Terlihat pepohonan di malam hari dengan bulan sabit terang di langit

\section{NARATOR \\ Matahari dan Bulan.}

Perlahan shot kamera pan ke atas mengarah kepada bulan sabit besar yang menyinari dunia

NARATOR

Kita melihat mereka setiap hari, tanpa mengetahui kisah di baliknya.

Kamera naik melewati awan-awan..

Tahukah kalian? Di balik setiap awan terdapat kisah yang baru. Dan yang ini menceritakan tentang cinta.

\section{DEEP TO WHITE}

\section{EXT. LANGIT- MALAM}

Terlihat seorang dewi berparas anggun, bertubuh gemulai, dan terlihat elegan sambil duduk diatas bulan sabit. Menangis.

\section{NARATOR}

Alkisah hidup seorang dewi Bulan dilangit malam.

Sang dewi terlihat murung, dan bersedih. Pandangannya kemudian mengarah ke atas, dan dari matanya jatuh setetes cahaya yang menyerupai air mata.

\section{NARATOR}

Ia sangat cantik jelita. Namun kesedihan menutupi keanggunan sang dewi. Ia menangis setiap hari, setiap malam. Dan dari tiap tetes air matanya akan berubah menjadi bintang. 
CLOSE pada cahaya kecil yang kemudian perlahan mulai berubah menjadi suatu bintang. Sang dewi pun mengangkat bintang kecil itu, dan menghempaskannya ke langit malam. Zoom out- Terlihat pemandangan sang dewi di tengah-tengah jutaan bintang di langit. FADE IN.

\section{NARATOR}

Jutaan bintang di langit, satu-satunya teman yang ia miliki di Dunia Malam.

TITLE: THE LONELY GODDESS: Dewi yang kesepian

ACT 2- MIDDLE

EXT. LANGIT DUNIA- MALAM - MENJELANG FAJAR

\section{NARATOR}

Hanya ada satu hal yang ia inginkan.

Tiba-tiba pandangan sang dewi berubah. Secerca cahaya muncul dari raut muka sang dewi yang tadinya menyiratkan penderitaan, menjadi sedikit tersenyum penuh harapan.

Terlihat cahaya terang matahari muncul dari balik bola dunia.

INTERCUT: Pemandangan matahari fajar dibumi.

\section{NARATOR}

Bertemu dengan Dewa Matahari.

Muncul seorang Dewa Matahari, bertubuh tegap, berparas tampan. Kuat dan Bercahaya. Ia berputar menyambut datangnya pagi. Sejenak mereka beradu pandang. Awalnya sang dewi ragu-ragu, namun melihat sang dewa di balik dinding dimensi ia pun tergerak. Namun mereka tidak bisa bersatu, mereka berputar dalam satu rotasi yang sama. Tidak akan bisa bertemu untuk selamanya.

\section{MONTAGE- TAKDIR YANG MEMISAHKAN}

-- Dari bumi: Fajar tiba dan bulan mulai menghilang

-- Penglihatan dari zoom out langit, yang memperlihatkan jarak bulan dengan matahari, Dewi Bulan dengan Dewa Matahari

-- Ekspresi masing-masing ketika mereka terpisahkan

\section{ACT 3- CRISIS}

EXT. PEMANDANGAN DI BUMI-SIANG-MALAM

Pemandangan matahari yang menyinari bumi.

\section{NARATOR}

Matahari naik ketika Bulan turun. Dan malam datang ketika berganti hari. Dan bulan yang menyinari bumi di malam hari.

EXT. LANGIT-MALAM-SIANG

Sang dewi bulan terlihat sedih. Gambarpun dibagi menjadi dua sisi. Sisi kiri dewa matahari dengan matahari yang penuh dengan kemarahan, dan sisi kanan Dewi Bulan yang lembut duduk termenung di samping bulan.

\section{NARATOR}

Layaknya kutukan bagi mereka untuk selalu terpisahkan. (beat)

...dan tidak akan bisa bersatu.

Waktu terus berlalu, bulan di samping sang dewi makin menjadi penuh. Namun hal itu tidak mengubah kenyataan bahwa mereka terpisahkan oleh jarak dan takdir. Mereka sama-sama menengadah ke atas. Seakan bertanya kapan mereka bisa bertemu. 


\author{
NARATOR \\ Lama menanti mereka pun bertanya. \\ "Berapa lama lagi mereka harus menunggu?”
}

EXT. LANGIT-MALAM

Sang Dewi masih termenung di atas bulan penuh. Suasana malam yang sepi. Suara lonceng terdengar dari kejauhan.

\author{
NARATOR \\ Dan jawaban pun... \\ (beat) \\ “...datang."
}

Bulan bergerak kembali. Sang Dewi hanya bisa mengikuti, tak lama muncul cahaya terang dari arah kanan sang dewi. Merasakan panas dipipinya yang kebiruan, ia pun menengok. Sang Dewa Matahari tersenyum menyambut sang Dewi. Jarak mereka masih jauh. Namun mereka tahu. 360 tahun telah tergenapi. Ini merupakan kesempatan mereka untuk bertemu.

\title{
EXT. PENGLIHATAN DARI BUMI
}

Terlihat Bulan mulai mendekati Matahari. Para mahluk bumi mulai besorak menunggu fenomena alam terjadi.

EXT. LANGIT

Saling bertatapan. Bisa dilihat seberapa tegangnya mereka menunggu saat ini. Jarak mereka semakin dekat. Terdengar degub jantung mereka berdebar kencang.

\section{EXT. PENGLIHATAN DARI BUMI}

Terlihat Bulan hampir secara penuh menutupi matahari.

\section{EXT. LANGIT}

CLOSE pada ekspresi masing-masing. Saat yang dinantikanpun tiba. Saat Matahari sejajar dengan Bulan, Sang Dewa kembali mengulurkan tangannya, Sang Dewipun menyambutnya dengan senyuman. Tangan merekapun akhirnya bersatu.

MONTAGE- GERHANA MATAHARI TOTAL

-- FLASHBACK Saat mereka terpisahkan dan tidak bisa bertemu.

-- Keadaan Gerhana Matahari Total di bumi

-- Spesial Efek ketika dunia siang dan malam bertemu dan melebur menjadi satu dari

kejauhan.

-- Dunia menjadi Gelap untuk seketika.

\section{ACT 5- ENDING}

\section{NARATOR}

Tetapi di setiap pertemuan pasti ada akhir.

Namun Gerhana Matahari Total tidak bertahan lama. 360 tahun menunggu, mereka diberikan waktu 7 menit untuk melepas kerinduan dengan jarak yang masih ada, mereka hanya bisa saling bergenggaman tangan. Matahari dan Bulan pun kembali bergerak kearah yang berlawanan. Dengan berat hati mereka harus melepaskan tangan masing-masing.

EXT. PENGLIHATAN DARI BUMI-GERHANA MATAHARI-SIANG

Gerhana Matahari mulai selesai. Bulan bergerak kembali. Pencahayaan mulai kembali menjadi siang. 


\section{EXT. LANGIT}

Bulan kembali menarik sang dewi menjauh dari sang Dewa Matahari. Mereka pun kembali ke posisi masing-masing.

\section{NARATOR \\ Matahari selayaknya menyinari siang. \\ Dan Bulan menyinari malam.}

ZOOM OUT Dunia kembali seperti sedia kala. Bulanpun kembali ke dunia malam.

\section{NARATOR}

Maka mereka pun menanti kembali.

EXT. BUMI-MALAM

Kembali ke pepohonan di Dunia nyata. Kembali ke langit dengan Bulan Sabit terang menyinari Bumi.

\section{NARATOR}

Hingga pertemuan mereka, yang akan datang.

FADE OUT.

\section{ENDS TITLE CREDIT}

\section{Perancangangan Visual sampai dengan Sinematografi}

Gaya visual sederhana dengan menonjolkan keunikan dalam desain digabung dengan hasil render yang realistis. Agar menjaga keseimbangan antara cerita fantasi (mitos) dengan cerita di dunia nyata. Aplikasi warna digunakan untuk pencapaian kesan indah, romantis dan klasik. Penggarapan untuk scene bumi divisualisasikan dengan kesan real dan scene langit lebih digarap dengan gaya visualisasi fantasi.

Penggarapan mood pada motion menggunakan teknik montage dengan deep to white dan deep to black. Visualisasi suasana temaram malam digunakan pewarnaan ke arah ungu gelap agar dicapai kesan keindahan malam dan pewarnaan ke arah jingga terang digunakan intuk suasana siang untuk mendapatkan kesan warm. Sedangkan pada scene pertemuan akan didominasi warna jingga ungu untuk pencapaian kesan romantik dan selanjutnya mengarah kehitaman sampai scene gerhana matahari total terjadi. Perancangan karakter mengacu pada referensi bentuk patung-patung Hindu Bali, dengan modifikasi kostum, ornament dan gaya tata rias perpaduan budaya Jawa dan Bali.

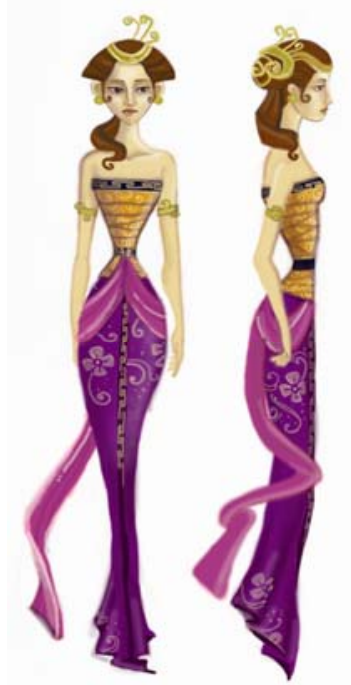

Gambar 1 Sketsa Konsep 2D Dewi Bulan 
Pada Gambar 1, tampak sketsa konsep 2D tokoh karakter Dewi Bulan yang merupakan tokoh utama dari cerita film pendek animasi ini. Sesuai hasil survey Dewi Bulan divisualissaikan sebagai figure ramping dengan karakter yang lembut, feminin dan berparas cantik. Kostum dirancang dengan perpaduan gaya kostum penari Bali yang dimodifikasi dengan kostum adat Jawa. Demikian pula dengan rancangan detail ornament dana gaya tata riasnya. Warna ungu dan kuning keemasan dipadu sebagai pencitraan keagungan dan keanggunan seorang Dewi.

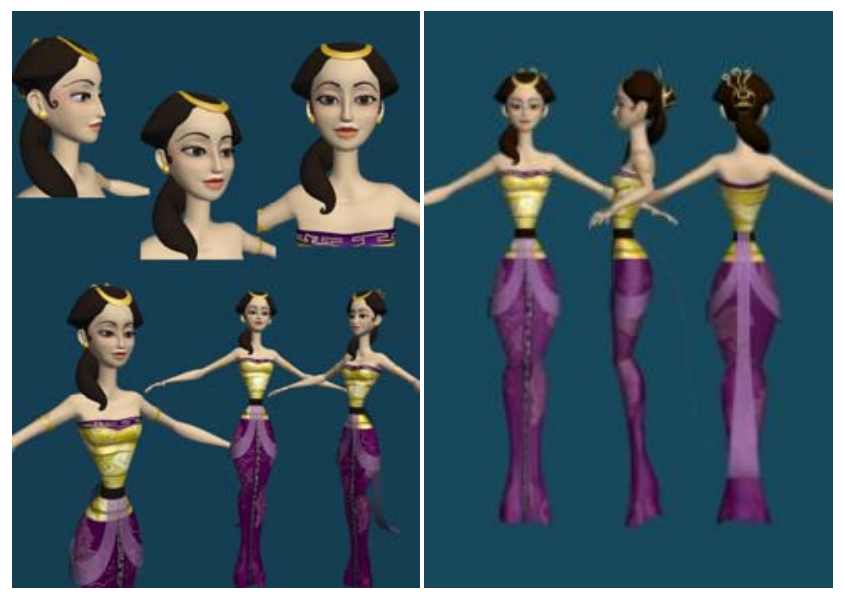

Gambar 2 Visualisasi 3D Dewi Bulan

Pada gambar 2 tampak visualisasi 3D tokoh karakter Dewi Bulan. Karakter yang merupakan tokoh utama ini selain divisualisasaikan sebagi figure yang feminin, lembut, cantik dan anggun, dalam beberapa scene seringkali divisualisasikan dengan ekspresi sedih dikarenakan alur cerita dimana Dewi Bulan larut dalam penantiannya yang begitu lama untuk bertemu dengan Dewa Matahari. Warna kulit ditampilkan dengan warna terang untuk menambah kesan keanggunan seorang dewi.

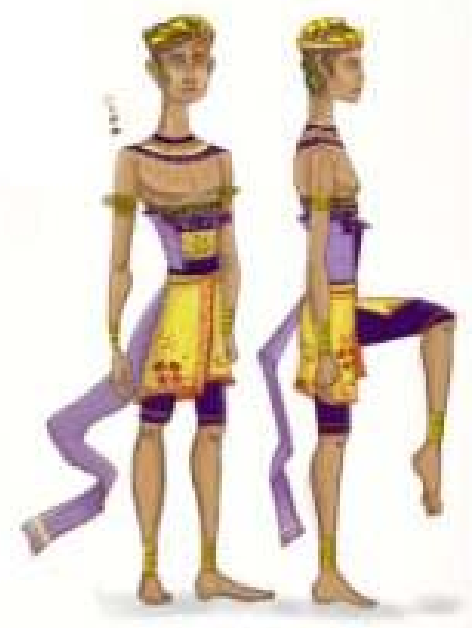

Gambar 3 Sketsa Konsep 2D Dewa Matahari

Pada gambar 3 tampak sketsa konsep 2D tokoh karakter Dewa Matahari yang juga merupakan tokoh utama dari cerita film pendek animasi ini. Sama halnya seperti rancangan karakter Dewi Bulan, kostum dirancang dengan perpaduan gaya kostum penari Bali yang dimodifikasi dengan kostum adat Jawa. Demikian pula dengan rancangan detail ornament hias dan gaya tata riasnya. Warna ungu dan kuning keemasan dipadu sebagai pencitraan keagungan dan keanggunan seorang Dewa. 


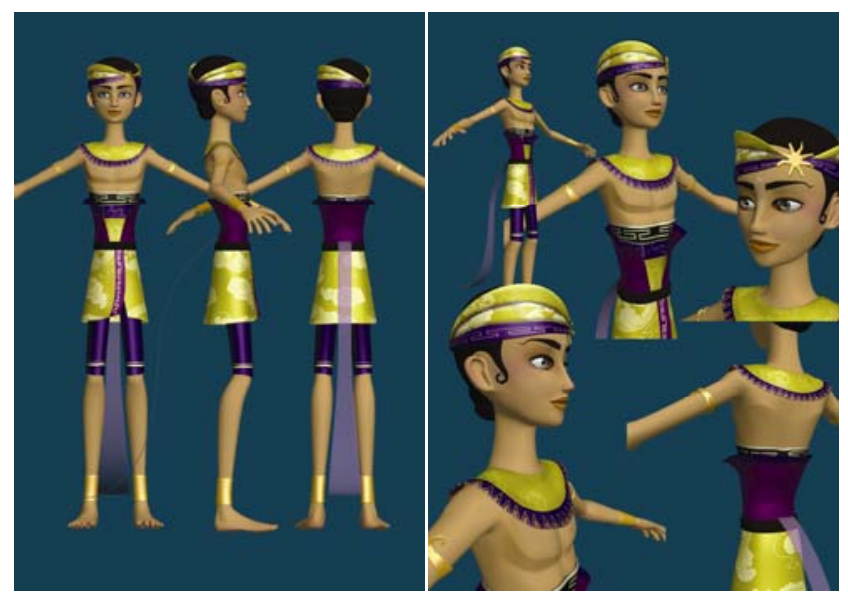

Gambar 4 Visualisasi 3D Dewa Matahari

Pada gambar 4 tampak visualisasi 3D tokoh karakter Dewa Matahari. Dewa Matahari merupakan penjaga matahari. Mereka digambarkan sebagai satu kesatuan. Sang Dewa memberikan kekuatan pada matahari untuk bersinar begitu juga Matahari yang membuat sang Dewa mempunyai kekuatan. Karakter Dewa Matahari divisualisasikan sebagai figure yang jantan, tegas dan kuat. Tidak seperti kuat pada umumnya yang digeneralisasikan oleh masyarakat Barat sebagai bentuk tubuh yang kekar, namun lebih divisualisasikan sebagai karkter dewa dengan bentuk tubuh kuat dengan karakter image Timur atau Indonesia. Warna kulit ditampilkan dengan warna agak gelap dengan ekspresi wajah yang cakap dan tenang.

Perancangan environment dalam film animasi pendek ini terbagi menjadi scene bumi dan scene langit. Scene bumi dirancang sebagai dunia nyata dan scene langit sebagai dunia fantasi.

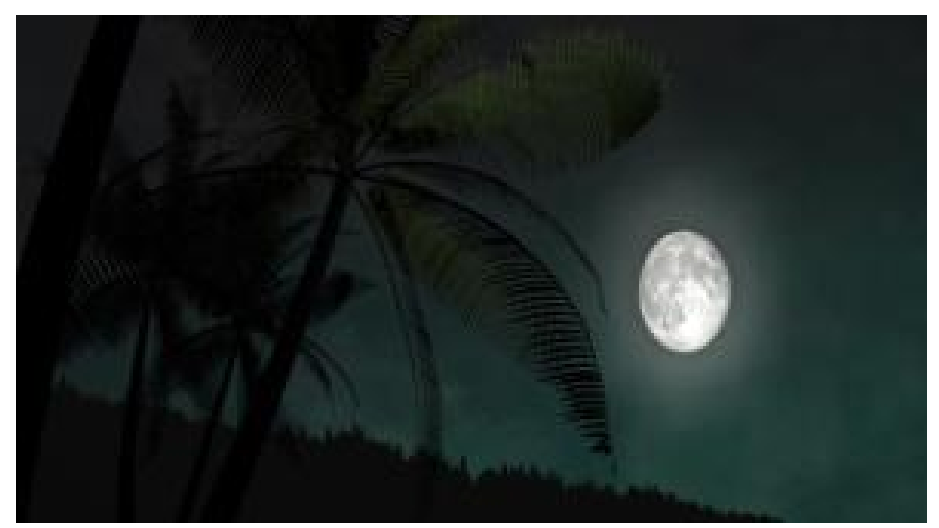

Gambar 5 Scene Bumi

Pada gambar 5 tampak scene bumi yang ditampilkan real dengan set extention di after effects, dan perpaduan antara matte painting dengan 3D render obyek. Diperlukan sekitar 7 set extention dalam film animasi pendek ini. Perancangan scene langit divisualisasikan sebagai perpaduan antara dunia siang dan malam. Kesan warna dunia fantasi ditampilkan sangat berbeda dengan tampilan scene bumi sebagai dunia real. Dunia malam didominasi warna biru keunguan dengan taburan gemerlap bintang sedangkan dunia siang ditampilkan dengan warna jingga cerah yang berpadu dengan unsur violet. Pewarnaan dunia siang lebih variatif untuk menampilkan perbedaan matahari senja, siang dan pagi hari. Unsur kelangitan lainnya ditampikan dengan konsep bentuk ornament sulur. 


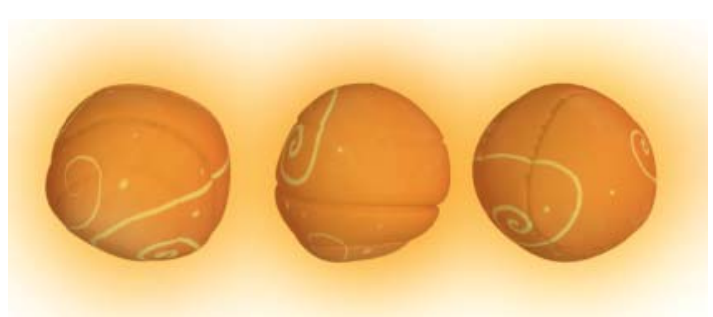

Gambar 6 Visualisasi 3D Matahari

Pada gambar 6 tampak visualisasi 3D matahari. Matahari tetap divisualisasikan sebagai sumber cahaya, benda yang mempunyai cahaya benderang di dunia siang. Bentuk bundar dimodifikasi menjadi agak terdistorsi hingga tidak sepenuhnya bundar dengan penambahan aksen motif sulur di beberapa area permukaannya. Hal ini untuk memperkuat kesan keunikan di dunia fantasi.

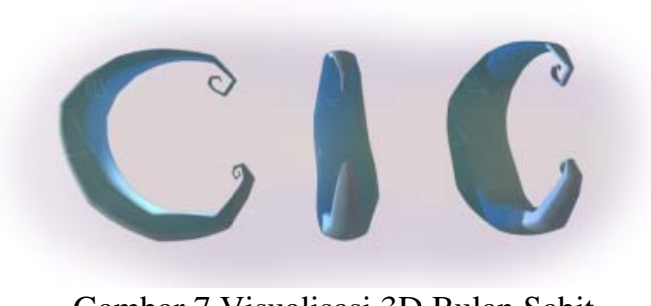

Gambar 7 Visualisasi 3D Bulan Sabit

Pada gambar 7 tampak visualisasi 3D bulan sabit. Bulan sabit divisualisasikan dengan bentuk terdistorsi dengan tetap menampilkan unsur bentuk dan ornament sulur. Penggarapan detail yaitu dengan mengaplikasikan elemen-elemen garis sulur putih yang berlatar belakang biru kehijauan.

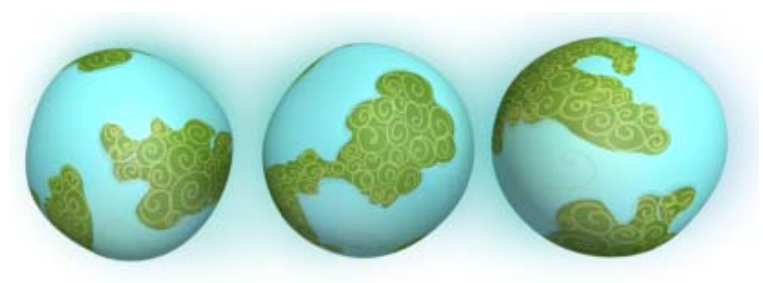

Gambar 8 Visualisasi 3D Bumi

Pada gambar 8 tampak visualisasi 3D bumi. Bentuk bundar dimodifikasi menjadi agak terdistorsi hingga tidak sepenuhnya bundar dengan penambahan tekstur motif sulur di area daratan. Pewarnaan menggunakan warna-warna yang selazimnya digunakan untuk menggambarkan bumi yaitu biru muda untuk lautan dan hijau untuk daratan.

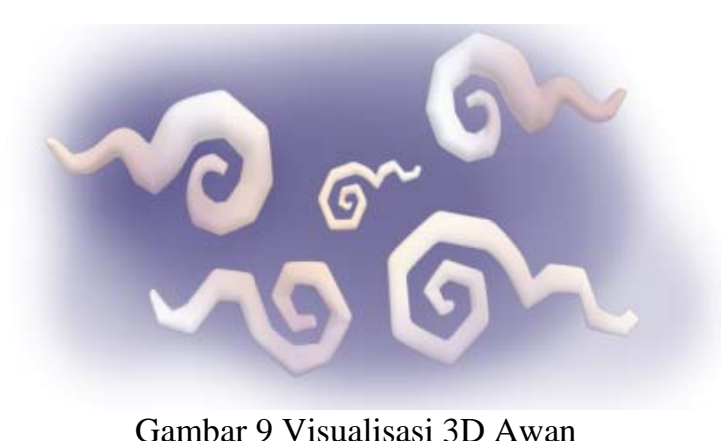

Gambar 9 Visualisasi 3D Awan 
Pada gambar 9 tampak visualisasi 3D awan. Bentuk dirancang dengan mengacu referensi bentuk awan pada pewayangan. Modifikasi bentuk stilasi awan dengan bagian ujung yang menyerupai sebuah ekor yang berlekuk-lekuk dinamis.

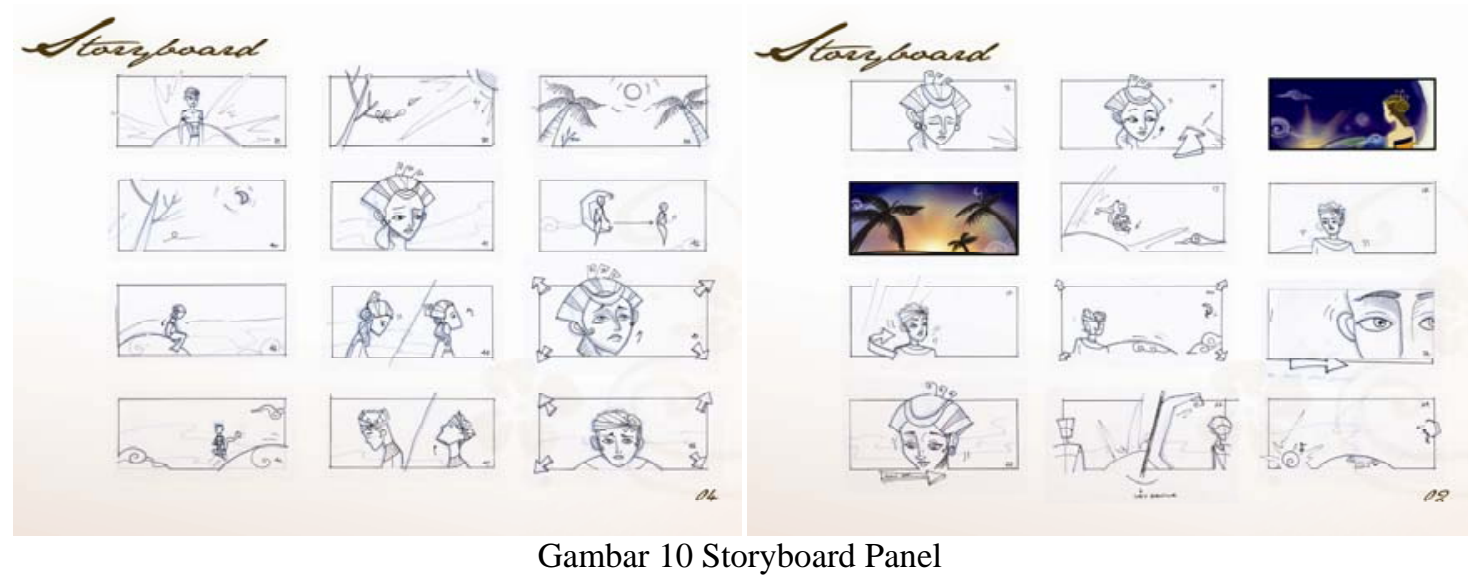

Pada gambar 10 dapat dilihat cuplikan rangkaian sketsa storyboard (jalan cerita) film animasi pendek "Dewi yang Kesepian.” Thumbnails (sketsa kasar) ini dirancang dan dirangkai sesuai dengan alur adegan yang telah ditetapkan di tahap perancangan tiap babak adegan skenario, untuk selanjutnya dijadikan acuan perancangan pada proses pengambilan gambar film.
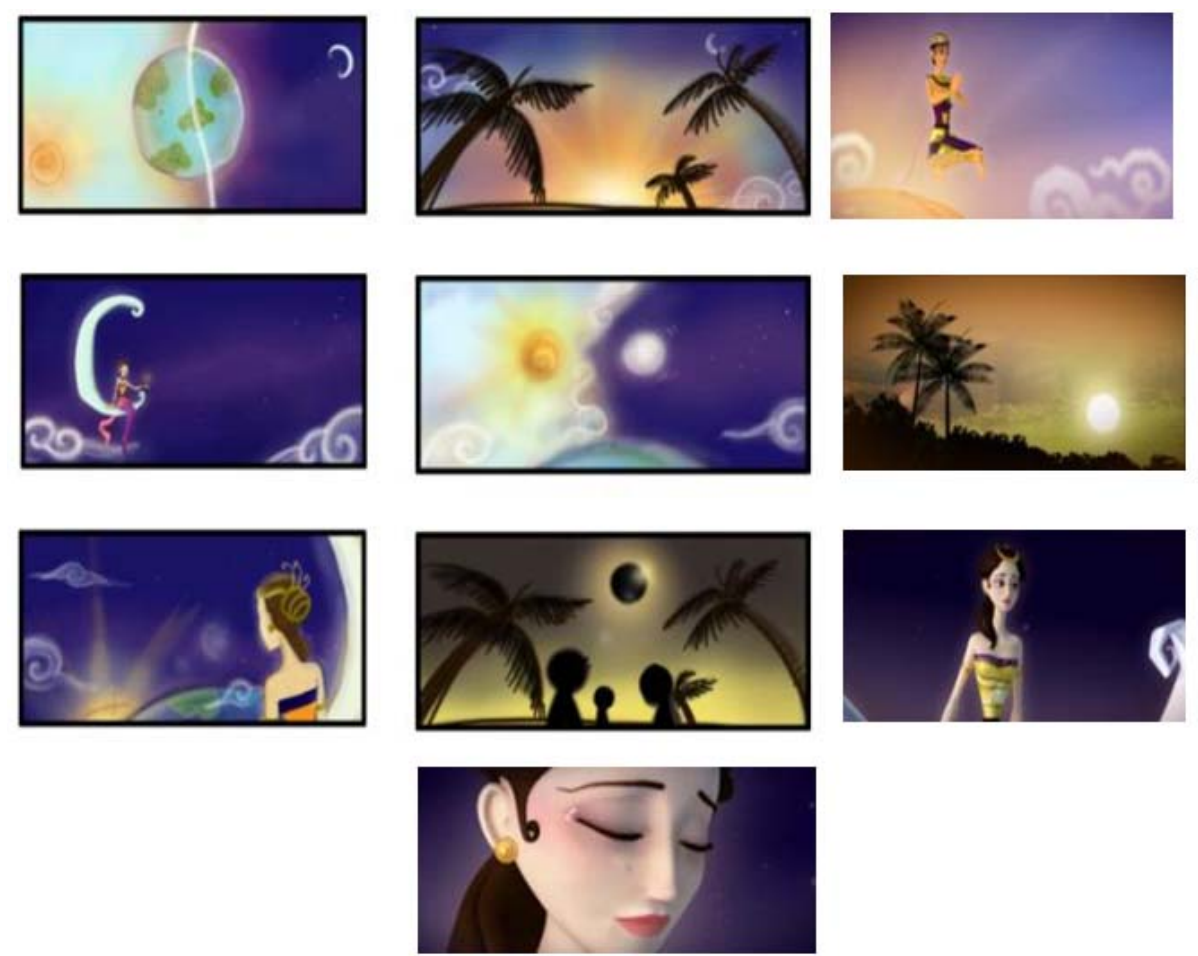

Gambar 11 Screenshot Film Animasi Pendek “Dewi yang Kesepian”

Pada gambar 11 dapat dilihat screenshot (cuplikan gambar adegan) dari film animasi pendek Dewi yang Kesepian, yang mengacu dari rancangan alur storyboard yang telah ditetapkan. 


\section{PENUTUP}

Indonesia merupakan negeri yang kaya akan budaya, dimana salah satunya yaitu budaya mitologi dewa dewi Nusantara. Namun pamor mitologi dewa dewi Nusantara kian pudar di kalangan genereasi muda anak bangsa.Media audio visual mempunyai peran efektif untuk menjangkau komunikasi dan edukasi masyarakat khususnya generasi muda. Pengembangan audio visual dengan kemasan dan tampilan keseluruhan yang menarik akan lebih membangkitkan minat dari target audience yang dalam hal ini khususnya adalah para remaja terhadap produk-produk film animasi lokal. Sehingga pesan moral yang ingin disampaikan dapat diterima dengan lebih mudah oleh para remaja. Dengan adanya pembuatan film pendek animasi lokal dengan tema mitologi dewa dewi ini akan membantu perkembangan animasi lokal di Indonesia sekaligus membantu pelestarian budaya. Tema sederhana yang mencerminkan, memperkenalkan budaya Indonesia dan dikemas dengan menarik dengan teknologi 3D, diharapkan dapat membuat masyarakat memetik hal positif dari film animasi pendek mitologi dewa dewi ini. Dengan adanya film animasi pendek Dewi yang Kesepian ini, disarankan agar perkembangan animasi dengan tema lokal dan berbudaya Indonesia dapat terus dikembangkan, agar generasi muda khususnya remaja semakin mencintai produk lokal dan dapat turut serta untuk mengembangkannya.

\section{DAFTAR PUSTAKA}

Capizzi, T. (2002). Inspired 3D modelling and texture mapping. USA: Premier Press.

Covarrubias, Miguel. (1946). Island of Bali. Periplus, Singapore.

Danaher, Simon. (2004). The Complete Guide to Digital 3D Design. ILEX, Cambridge.

Djalle, Zaharuddin. (2007). 3D Animation Movie. Informatika Bandung, Bandung.

Durkheim, Emile. (1992). Sejarah Agama; The Elementary Forms of the Religious Life. Ircison, New York.

Hartini, Dwi. (2006). Pertumbuhan dan Perkembangan Agama Kebudayaan Hindu-Buddha di Indonesia.

Ismail, Muhammad. (2009). Ensiklopedi Matahari dan Bulan. DIVA Press, Yogyakarta.

Kurtti, Jeff dkk. (2009). The Art of “The Princess and The Frog”. Chronicles Books, San Fransisco.

Schroeder, Russell dkk. (2002). Disney The Ultimate Visual Guide.A Darling Kindersley Book, London.

Spies, Walter dkk. (2002). Dance \& Drama in Bali. Periplus, Singapore.

Tim Optima Pictures. (2009). 101 Cerita Nusantara. PT. Transmedia Pustaka, Jakarta

White, Tony. (2009). How to Make An Animated Films. Focal Press, Burlington. 